\title{
Social-ecological mismatches create conservation challenges in introduced species management
}

\author{
Erik A Beever $^{1,2 \star}$, Daniel Simberloff ${ }^{3}$, Sarah L Crowley ${ }^{4}$, Robert Al-Chokhachy ${ }^{1,2}$, Hazel A Jackson ${ }^{5}$, and Steven L Petersen ${ }^{6}$
}

Introduced species can have important effects on the component species and processes of native ecosystems. However, effective introduced species management can be complicated by technical and social challenges. We identify "social-ecological mismatches" (that is, differences between the scales and functioning of interacting social and ecological systems) as one such challenge. We present three case studies in which mismatches between the organization and functioning of key social and ecological systems have contributed to controversies and debates surrounding introduced species management and policy. We identify three common issues: social systems and cultures may adapt to a new species' arrival at a different rate than ecosystems; ecological impacts can arise at one spatial scale while social impacts occur at another; and the effects of introduced species can spread widely, whereas management actions are constrained by organizational and/or political boundaries. We propose strategies for collaborative knowledge building and adaptive management that may help address these challenges.

Front Ecol Environ 2019; doi:10.1002/fee.2000

lthough it is relatively easy to rally people around the idea of controlling populations of invasive introduced species such

\section{In a nutshell:}

- Effective management of introduced species can be challenged by "social-ecological mismatches" (differences in the function and scale of social and ecological systems)

- Introduced species can affect social and ecological systems differently: for example, by providing positive social benefits at one scale while having negative ecological impacts at another

- Social and ecological systems may also respond or adapt to introduced species at different rates; for instance, cultural acclimatization may occur more rapidly than evolutionary adaptation

- Managing authorities may also be spatially or temporally constrained in ways that make effective management over large distances and timescales difficult

- Addressing social-ecological mismatches will be important for effective management of introduced species; this will require early, meaningful communication about complex management issues among researchers, managers, and the public, and a collaborative search for practical solutions and compromises

${ }^{1}$ US Geological Survey, Northern Rocky Mountain Science Center, Bozeman, MT ${ }^{*}$ (ebeever@usgs.gov); ${ }^{2}$ Department of Ecology, Montana State University, Bozeman, MT; ${ }^{3}$ Department of Ecology and Evolutionary Biology, University of Tennessee, Knoxville, TN; ${ }^{4}$ Environment and Sustainability Institute, University of Exeter, Penryn, UK; ${ }^{5}$ Durrell Institute of Conservation and Ecology, School of Anthropology and Conservation, University of Kent, Canterbury, UK; ${ }^{6}$ Plant and Wildlife Sciences Department, Brigham Young University, Provo, UT as cheatgrass (Bromus tectorum), zebra mussels (Dreissena polymorpha), Norway rats (Rattus norvegicus), and brown tree snakes (Boiga irregularis), when charismatic species, both native and non-native, are a conservation problem, management increasingly leads to complex and high-profile controversies.

Scale has proven to be both fundamentally important to, and an organizing concept for, ecology and conservation biology (eg Wiens and Bachelet 2010), particularly in landscape and disturbance contexts. Here, we highlight a number of case studies to argue that scale - and specifically mismatches of scale between social and ecological systems (ie "social-ecological mismatches"; Cumming et al. 2006) - is also a key influence on many conflicts involving introduced-species management.

Despite abundant evidence that introduced species often cause environmental damage, economic disruption, or both (Simberloff et al. 2013), and that the impacts may be subtle and delayed (Crooks 2011), introduced-species management frequently generates controversy and conflict (Crowley et al. 2017). The reaction to management and any ensuing conflicts are tightly linked to the specific invading species, as well as to ecological and sociopolitical contexts. Generally, management conflicts arise as a result of (1) opposition from those members of society who derive profit or other socioeconomic benefits from the invading species (eg wildlife-viewing or fishing guides); (2) divergent personal or moral values between opponents and proponents of management (eg opposition by animal-rights or -welfare advocates to eradication campaigns targeting sentient species, normally introduced mammals and birds); or (3) the spiritual or cultural importance of the species to local inhabitants (Estévez et al. 2015). Charismatic animal species (Table 1) are often the focus of these controversies, but similar arguments also occur over management of introduced 


\begin{tabular}{|c|c|}
\hline Attribute & Humans typically like species that... \\
\hline Aesthetics & are physically attractive \\
\hline Intelligence of the animal & have greater cognitive capacity \\
\hline Phylogenetic relatedness to humans & are more advanced (less primitive) \\
\hline Size of the species & are larger \\
\hline Economic value of the animal & $\begin{array}{l}\text { are of positive (or non-negative) economic } \\
\text { value }\end{array}$ \\
\hline Perceived dangerousness to humans & are not common to wet and dark places \\
\hline $\begin{array}{l}\text { Likelihood of inflicting property } \\
\text { damage }\end{array}$ & $\begin{array}{l}\text { are unlikely to inflict human injury or property } \\
\text { damage }\end{array}$ \\
\hline Cultural and historical importance & are culturally and historically valued \\
\hline Animal relationship to human society & $\begin{array}{l}\text { are pets, farm animals, or game species; are } \\
\text { not pest or exotic species }\end{array}$ \\
\hline Predatory tendencies & are not predatory \\
\hline $\begin{array}{l}\text { Skin texture and morphological } \\
\text { structure }\end{array}$ & are not oily or slimy \\
\hline Mode of locomotion & do not crawl or squirm \\
\hline
\end{tabular}

insects, rats, and plants. For example, introduced horses are often appreciated because they are large, mammalian, not dangerous to humans, not predatory, are kept as pets and farm animals, and have widespread cultural and historical value in travel, agriculture, and warfare. Similarly, parakeets are popular because they are kept as pets, are not dangerous to humans, and have beautiful plumage. There may be opposition to the proposed management method (eg use of rodenticide), to the ultimate goal (eg eradication or population reduction), or to the fact that a species is targeted for management at all. Whatever its basis, such opposition has delayed and even led to the cancellation of management projects (Crowley et al. 2017).

Here, we demonstrate how the perceived costs and benefits of introduced species vary according to different stakeholder values, as well as with the temporal and spatial scales at which introductions are considered. We also show how the spatial or temporal scales at which management approaches may be feasible or socially acceptable may be inadequate to address impacts occurring at different, often larger, scales.

An example of a mismatch of stakeholder values related to spatial scale is that of Australian pine (Casuarina equisetifolia) introduced to Florida. Australian pine has many adverse ecological impacts both coastally and inland, but local attempts to remove it often elicit objections from citizens who value the benefits provided by the trees, such as shade (Simberloff 2011). A frequent example of a mismatch between feasibility and scale is eradication (total removal of every individual from a discrete population) of a species, which can often be successful, but because it requires putting all individuals within the range at risk, a single landowner refusing to participate in the initiative can stymie the entire effort, as happened recently with the Gambian pouched rat (Cricetomys gambianus) in
Florida (Witmer and Hall 2011). In the examples below, we describe several controversies that have arisen as a result of attempts to manage populations of several introduced species, and highlight aspects of each dispute that constitute socialecological scale mismatches. We conclude by suggesting how the challenges presented by these mismatches might best be tackled. A fourth case study is presented in WebPanel 1, and additional information about the three case studies discussed below is presented in WebPanel 2 (which also includes discussion of monk parakeets, Myiopsitta monachus).

\section{Case study 1: free-roaming horses}

Currently, native horses (Equus caballus) occur (as a result of reintroductions) in just three small areas of the Mongolian steppe. In contrast, because of their central role in human history and consequent widespread importance to many cultures (Table 1), free-roaming horses have been introduced to 18 countries across all continents except Antarctica (Beever 2013). Introduced horses have had varying ecological effects on native ecosystems in different parts of the world (Rogers 1991; Zalba and Cozzani 2004; Nimmo and Miller 2007), and public perceptions of horses' ecological roles and conservation-management actions have been correspondingly diverse. For instance, an estimated 400,000-1 million horses (called "brumbies") roam free in the Outback of central Australia (M Zabek pers comm), up from an estimated 300,000-600,000 horses in the early 1990s (Dobbie et al. 1993); those deemed to be "excess" are culled by helicopter-based sharpshooters to minimize horse starvation and to conserve aridland resources. However, despite some collaborative decision-making processes, this culling has sparked both local and regional public outrage. The contentiousness in Australia over the fate of these horses may reflect "their pluralistic status as an introduced pest [with documented ecological effects] and a national icon" (Nimmo and Miller 2007; bracketed text added to reflect remainder of that article's argument). In New Zealand, free-roaming horse populations in the Kaimanawa Range have high annual population growth rates (Rogers 1991; but see Linklater et al. 2004) and are culled annually to maintain a population of $\sim 500$ individuals, in an attempt to control grazing impacts on indigenous plant species (Fleury 2006). In the Pampas grasslands of Argentina's Ernesto Tornquist Provincial Park, the growth rate of an unmanaged horse population has averaged 6\% per year since its introduction in 1942, which has led to reduced native herbaceous vegetation cover and facilitated the establishment of an invasive pine species (de Villalobos et al. 2011). This latter result conflicts with the Park's fundamental management goal of conserving relict Pampean grasslands. In the Oostvaardersplassen Reserve in the Netherlands - a fenced reserve where managers seek to allow natural processes to govern dynamics to the greatest degree possible - red deer (Cervus elaphus), Heck cattle 
(Bos taurus), and Konik horses (E caballus) were introduced to limit woody plant encroachment, and have been left unmanaged and without large predators since the 1980s (Vulink 2001). Because the reserve is small, visitors could observe animals dying of old age or starvation, which led to societal concerns regarding the ethical treatment of the animals. Cattle populations in the reserve are declining as a consequence of the more rapid population increases of horses and red deer; collectively, all of these conditions have led managers to cull old and sick horses by sharpshooting, which has also raised public concerns (Vulink 2001).

In North America, areas currently or recently occupied by free-roaming horses (Figure 1a) span 36.7 million ha scattered across the western US, as well as parts of another 11 states, four Canadian provinces, and Mexico. In Canada, horses engender conflicting opinions regarding competing ecological objectives and priorities but also hold a unique position in the traditions and management practices of many First Nations people (Bhattacharyya and Murphy 2015). Across the western US, annual herd growth rates have averaged $8-30 \%$ (with long-term means between 16-22\%), driven in part by the provision of artificial sources of water and forage, as well as low predation (Beever 2003; NRC 2013). These mean values, which are high by large-mammal standards, reflect the removal of processes (predation and lack of water) that commonly lead to density-dependent mortality. Such high growth rates, compounded by the fact that the only socially acceptable management options include immunocontraception and removing animals to holding facilities, dictate that (1) there are greater than 2.8 times more horses on the range than is prescribed by the US Bureau of Land Management's (BLM's) high estimate of appropriate management level (AML) on BLM-administered lands (and 4.7 times more horses than the BLM low-end, more conservative AML estimate); and (2) holding-facilities costs ( US $\$ 47.54$ million per year) constitute $58.34 \%$ of the entire budget of the BLM's Wild Horse and Burro Program (Garrott and Oli 2013; BLM data: https://on.doi.gov /2Cw431y). Moreover, most current horse removals are under litigation, further complicating the management challenges.

\section{Temporal and spatial scale in social versus ecological processes}

For introduced horses, social-ecological mismatches are seen through the dissimilar time frames of the natural phenomena and of the management responses that affect free-roaming horses. Natural phenomena such as drought, fire, and invasive plant outbreaks, which influence horses and mediate their effects on ecosystems, can have their most-pronounced effects last from a few days to a few months, whereas making comprehensive plans or altering policies can require months to years (Linklater et al. 2002). Planning is further
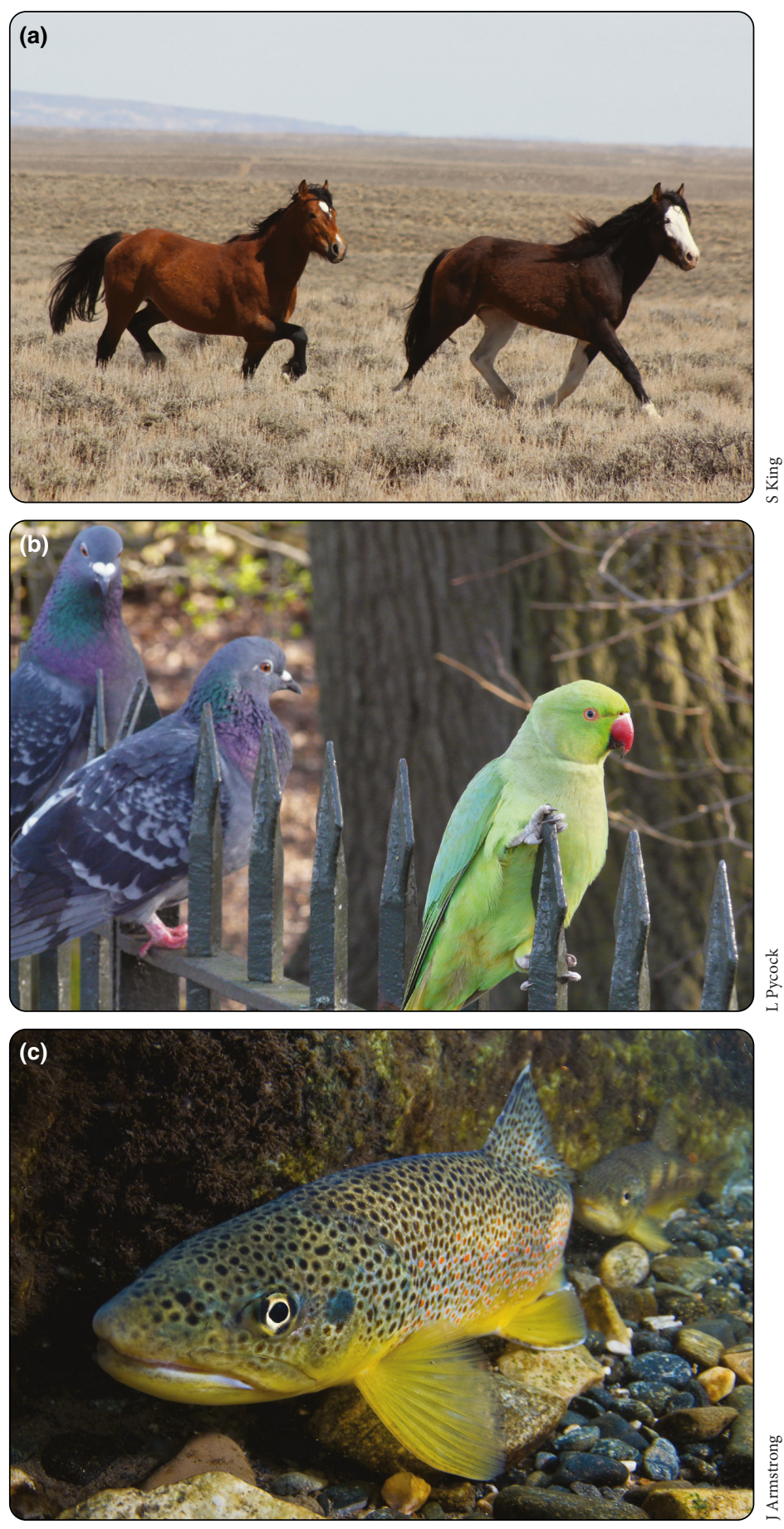

Figure 1. Charismatic or otherwise attractive introduced species, including: (a) free-roaming horses (Equus caballus) in sagebrush-steppe in the Little Colorado Herd Management Area, Wyoming; for many people freeroaming horses symbolize wildness, power, freedom, and an idealized "Wild West"; (b) strikingly beautiful ring-necked parakeets (Psittacula krameri) and feral domestic pigeons (Columba livia domestica) in an urban area in the UK; (c) brown trout (Salmo trutta) in New Zealand, illustrating that a species' attractiveness may also stem from the economic values and recreation it provides; and (in WebFigure 1) strawberry guava (Psidium cattleianum) in Hawaii, which has decorative and culinary values. In all cases, temporally, a snapshot ignores the ecological trends that become apparent over longer timescales, and spatially, close-up images mask ecological consequences that often occur at broader extents. 
complicated by annual cycles of management agency funding appropriations. These mismatched time lines hinder agencies' ability to balance short-term flexibility and long-term adaptive management.

Agencies also face mismatches in the spatial resolution of the ecological impacts of horses and of the policies enacted to cope with these effects. Because free-roaming horses have location-specific influences on ecosystem functions and composition, the specific indicators and resource levels that trigger management responses may differ across ecoregions. Nonetheless, management in the US is often grounded in highly generalized information about policy and ecology, and frequently reflects national sociopolitical dynamics. A desire for repeatability and standardization of management practices across districts and state-level BLM and US Forest Service offices (to facilitate multiscale analyses and planning) is countered by the value of having locally tailored control and implementation. Furthermore, while the positive effects of horses are most visible at a national scale (eg those lauded by influential supporters who often live far from horse-occupied areas), negative impacts - both social and ecological - are usually experienced locally. Management programs are also complicated by the extensive number of laws and policies relevant to wild horse management, each of which operates on a unique spatiotemporal scale (WebTable 1). More pragmatically, although free-roaming horses can travel up to $28.3 \mathrm{~km}$ per day (Hampson et al. 2010) and can travel up to $65 \mathrm{~km}$ away from water to obtain food (Berman 1991), free-roaming horses on BLM-administered land are restricted by law to remain in static Herd Management Areas (HMAs), whose comparatively small sizes and hardened borders (due to permanent fencing and boundaries that are static across seasons and years) do not permit the extensive movements that could allow horses to evade severe weather. However, this particular mismatch has recently been addressed in some places by BLM designation of more extensive "management complexes" that lump adjacent HMAs in the US together.

The challenge of introduced horses in Australia is arguably more acute than in the US. Since free-roaming horses were introduced to Australia in 1778, their population on the continent has grown to be larger than all other global free-roaming horse populations combined, and horses are now competing with native wildlife for limited water and forage at landscape scales (D Berman pers comm). Horses have been shown to travel in excess of $100 \mathrm{~km}$ (one-way) to search for water and forage (B Hampson pers comm); such distances may encompass multiple management and legal jurisdictions, and may not align with the local scales at which management actions typically occur.

\section{Case study 2: parakeets in Europe}

Parrots (Psittacidae spp) have been popular as pets for centuries due to their colorful plumage (Figure $1 \mathrm{~b}$ ), engaging behavior, and intelligence. The global transport of exotic birds for the pet trade has resulted in many parrot species escaping captivity and becoming established in the wild outside of their native ranges (Reino et al. 2017). The ring-necked parakeet (Psittacula krameri) is one of the most widely distributed parrot species in the world. Native to Asia and sub-Sahel Africa, ring-necked parakeets currently occur in over 35 countries across five continents. Primarily residents of urban areas, these parakeets are for many a novel and welcomed addition to local parks and gardens, but they will likely become a familiar sight for future generations. In their nonnative ranges, they compete with native birds and bats for nesting cavities (eg Eurasian nuthatches [Sitta europaea] in Belgium, greater noctule bats [Nyctalus lasiopterus] in Italy and Spain [Menchetti et al. 2016], echo parakeets [Psittacula eques] in Mauritius [Tatayah et al. 2007]). For countries with endemic parrot species, ring-necked parakeets can also pose a serious disease risk; for example, they can transmit Psittacine beak-and-feather disease to endangered echo parakeets (Kundu et al. 2012). More recently, ring-necked parakeets in the Seychelles archipelago were targeted for eradication because of the disease risk they pose to the endangered Seychelles black parrot (Coracopsis barklyi). Ringnecked parakeets can also cause economic and societal impacts; for example, this species is considered a severe crop pest in their native Asian range, and agricultural damage has now also been observed in several EU countries, including to vineyards in the UK (although these impacts are still relatively limited in extent) and almond and sunflower plantations in Israel (Menchetti et al. 2016).

\section{Spatial and temporal scale in social versus ecological processes}

Parakeets are usually released in cities (Figure 1b), where they are widely appreciated, have had negligible economic impacts, and where there may be comparatively little biodiversity to affect. However, the greatest ecological impacts of these birds may be seen farther afield (eg Figure 2b; or through the spread of disease to an endemic population or in the damage done to rural agriculture by expanding populations; Menchetti and Mori 2014). Because managing authorities often have limited resources, there may be little incentive to manage parakeets so long as populations remain urban and localized, but inaction in these locations and at these scales could have far-reaching ecological consequences. This disparity between the extent of ecological impact and the extent of management activity is another example of a spatial mismatch.

This species also presents social-ecological mismatches across temporal scales. Many introduced parakeet populations subject to eradication or control under contemporary initiatives have been present for years to decades. Although these time frames are short in ecological terms (and populations are still small enough to be eradicated or controlled), they are long enough for local communities to become accustomed - and often emotionally attached - to the presence of introduced 
parakeets (see Crowley et al. [2018] for monk parakeets [Myiopsitta monachus]). Resident communities that experience parakeets in "human time" may therefore come to value them in a different way than ecologists and environmental managers who evaluate parakeets in relation to "ecological time". This temporal mismatch makes it difficult for ecologists to communicate precaution-based management in places where parakeets have been established for many years without obvious impacts, or to convince the public that, once established, such introduced populations may suddenly grow explosively, at which point control or management becomes impossible. Ecologically minded managers - whose values are formed relative to a specific, ecological understanding of time - may therefore find it challenging to convince local residents that "rapid-response" control is urgently necessary, particularly when personal experiences and local histories do not fit the typical picture of rapidly spreading, high-impact, introduced species (Crowley et al. 2018).

\section{Case study 3: global introductions of salmonids}

Salmonids (eg trout, char, salmon) are cold-water fishes that have been introduced worldwide for recreational angling and, in some instances, aquaculture (Klemetsen et al. 2003; Halverson 2011). The most common introductions have been of rainbow trout (Oncorhynchus mykiss), native to East Asia and western North America; and brown trout (Salmo trutta; Figure 1c), native to Europe, North Africa, and western Asia. Both species now have self-sustaining populations on every continent except Antarctica and are considered among the world's worst invasive species (ie have the most serious impact on biological diversity and/or human activities) (Lowe et al. 2004).

Although mechanisms of invasion may differ between the two species (Young et al. 2010), the ecological effects of introduced rainbow trout and brown trout for native species and ecosystems have been extensively documented. For example, in New Zealand, Australia, and South America, salmonid introductions have altered aquatic communities and led to population declines, behavioral shifts, and restricted geographical ranges of native Galaxiidae species (eg mudfish, kokopu, spotted minnow; Townsend 2003). Such effects on native aquatic assemblages have also been seen, along with other effects (eg altered food webs) in North America (Figure 2c; eg Budy et al. 2013), Africa (eg Kadye et al. 2013), Europe (eg Blanchet et al. 2007), and Asia (eg Morita et al. 2004). Thus, non-native salmonids constitute one of the greatest impediments to the conservation and persistence of numerous native fishes worldwide (eg Muhlfeld et al. 2017).

\section{Spatial and temporal scale in social versus ecological processes}

Increasingly ambitious actions to confront populations of rainbow trout and brown trout continue to be hampered by tensions among economic, political, social, and ecological
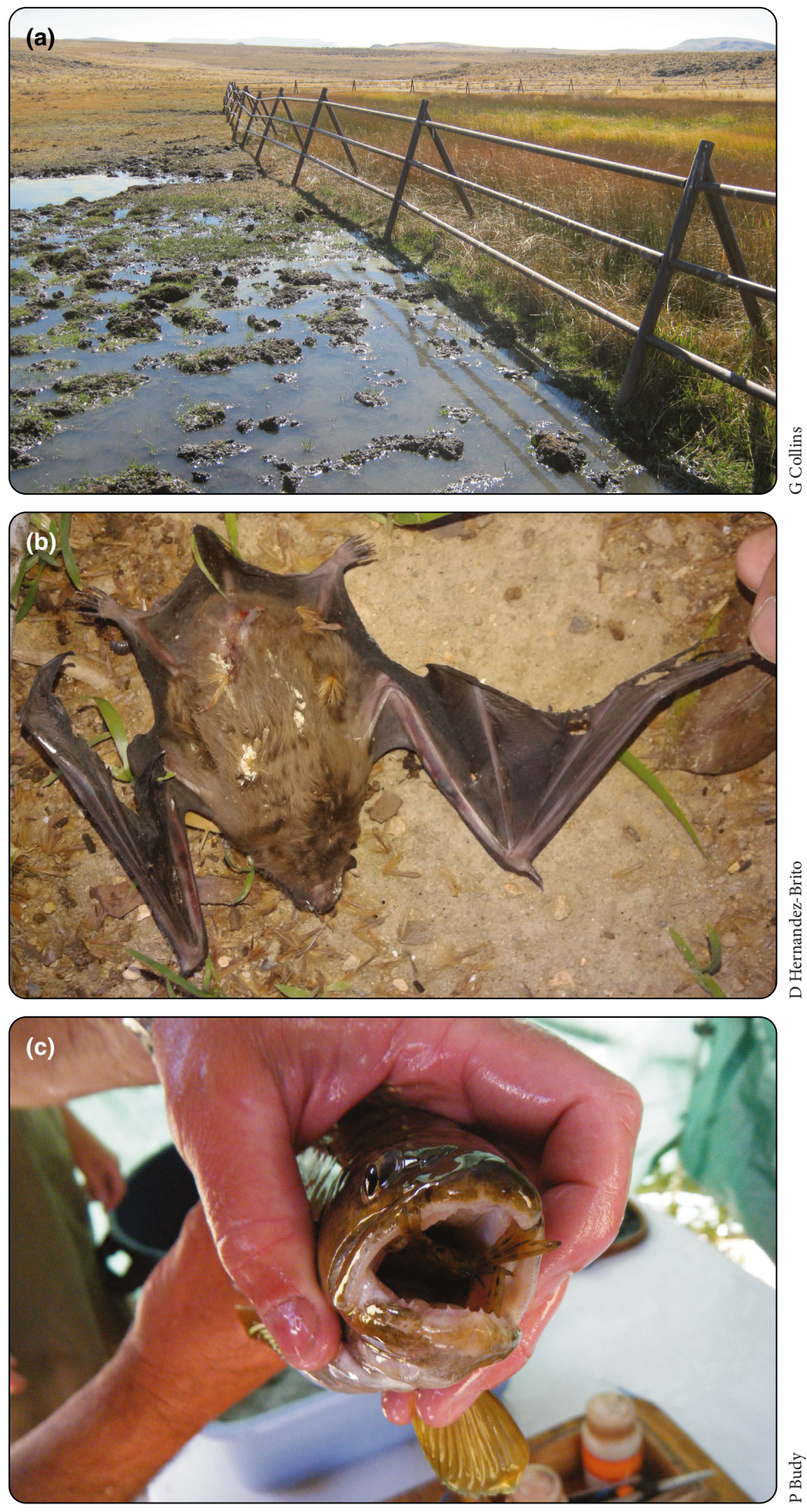

Figure 2. Examples of ecological consequences of introduced species seen at different spatial and temporal scales than those of Figure 1. (a) In rural, semi-arid southeastern Oregon, in a National Wildlife Refuge from which livestock have been excluded for over two decades, use of water holes by free-roaming horses can lead to fouling of water quality (eutrophication) and soil compaction, especially during dry seasons or years. Effects of grazing by horses are more clearly quantified by comparing grazed areas outside the fence with ungrazed areas inside the fence (although native herbivores can also access and graze in both areas). (b) Ring-necked parakeets can attack greater noctule bats (Nyctalus lasiopterus); in this case, the wounds on the bat's wings and abdomen led to the bat's death shortly after the attack. (c) In Utah, introduced brown trout prey upon native Bonneville cutthroat trout (Oncorhynchus clarkii utah); when combined with competitive interactions, such predation can lead to species replacement and community shifts. 
forces. The pursuit of wild introduced trout is a global phenomenon, with anglers traveling thousands of miles and the economic values of angling reaching tens to hundreds of millions of US dollars per year. Such mega-industries contrast with the situation for native galaxiids, which have little recreational value and suffer from the challenges of undervalued native taxa (Bockstael et al. 2000). The global draw of anglers pursuing introduced salmonids in foreign locations is spatially mismatched with the local, often endemic non-game taxa. Furthermore, introduced salmonids often have stronger legal protection than do native galaxiids (García de Leaniz et al. 2010), likely owing to the socioeconomic pressures related to the angling and tourism industries. Spatially, the legal protections of non-native salmonids typically extend to smaller headwater streams, despite the fact that angling is not common in these areas, so that there is little incentive for the angling industry to preserve such habitats. However, this lack of protection essentially eliminates the possibility of these areas serving as critical refugia for native species (Jackson et al. 2004). This mismatch between regulations, anglers, and native taxa constitutes a complete breakdown of the social-ecological system (Epstein et al. 2015).

In Australia, the US, and other countries, non-native salmonids occur within national parks, which challenges the goals and ideals of these areas as natural reserves for native species (eg the US National Park Service [NPS] Organic Act of 1916 [16 US Code 1, 2, 3, and 4]). National parks serve as national- to global-scale resources, providing millions of people from across the country and the world with opportunities to interact with native environments. These reserves with global value are strongly spatially mismatched with local angling industries that resist efforts to control nonnative salmonids. The mission statement of the NPS Organic Act calls for national parks in the US to serve as "unimpaired [areas] for the enjoyment of future generations" - a management mandate temporally mismatched with both (1) focus on short-term profit and recreational enjoyment (by the angling contingent), and (2) the time lags that may occur before established populations of introduced species begin to wreak exponentially more ecological havoc. With each generation of anglers and industry, the social challenges become increasingly insurmountable for conservation of less charismatic, non-sportfish taxa, as the cultural baseline becomes progressively more cemented (Pauly 1995). The cultural values of introduced salmonids have been present at local scales for many decades or longer, yet efforts to assess their impacts are relatively new (eg Soga and Gaston 2018). This temporal mismatch hampers efforts to bolster the often less charismatic native taxa and stem the accelerating losses of freshwater biodiversity (Dudgeon et al. 2006).

\section{Conclusions}

For the past several decades, management of introduced species has been one of the most divisive issues in managing public lands, especially in North America, Europe, Australia, and New Zealand (Linklater et al. 2002). Although more straightforward in a purely ecological sense, management of hyperabundant native species (eg white-tailed deer [Odocoileus virginianus], Canada geese [Branta canadensis], European badger [Meles meles]) can also stir up controversy, especially when these species are vectors of communicable diseases (eg European badgers as reservoirs for bovine tuberculosis) or affect private property (eg rodents in attic spaces). Public natural resource managers often find themselves caught between the opposing goals of a diverse range of stakeholders whose priorities can strongly conflict with the objective of maximizing ecological integrity. The controversy over attempts to manage introduced strawberry guava (Psidium cattleianum) in Hawaii (WebPanel 1; WebFigure 1) is similar: the concern of residential landowners over spillover to their properties of a biological control agent (namely, a scale insect) released in native forest, and anger among native Hawaiians at the prospect of the federal government eliminating introduced feral pigs, the removal of which they have strenuously resisted. Because feral pigs cause a cascade of ecological alterations in island ecosystems, and because strawberry guava is a staple food for pigs, efforts to reduce guava were perceived as an effort to eliminate pigs and thus interfere with the cultural tradition of pig hunting.

Although many conflicts arise between managers (who often have ecological training) and interested communities, owing to differences in their values and perceptions of risk posed by introduced species (Estévez et al. 2015), it is important to understand why and how such differences arise. For example, across our case studies, we find that the value placed by the public on horses (Beever and Brussard 2000), parakeets, and trout develops in relation to different timescales than ecologists' valuations and management goals. Whereas ecologist-managers tend to view horses negatively and as a relatively recent, disruptive ecological influence (Figure $2 \mathrm{a}$ ), the general public views them positively, partially because horses are perceived to be an integral part of social history. Introduced parakeets, even at the earliest stages of their establishment, can become a distinctive component of primarily urban spaces, and as generations pass, introduced salmonids become more embedded within local traditions and practices. Our case studies therefore demonstrate shifting baselines of public perceptions of introduced species, which continue along a spectrum from newly established species (eg parakeets) to those culturally ingrained for decades to centuries (eg salmonids, free-roaming horses). Arguably, some of the previous "natural" baselines are themselves in part cultural and may have developed amidst longestablished human introductions (eg dingoes [Canis lupus dingo] in Australia). Conversely, given geographic range shifts that species are undergoing because of contemporary climate change, many conservation managers are beginning to grapple with the ecological implications of new arrivals of regionally native species inside the (fixed) borders of man- 
agement units. For example, a hypothetical species whose range used to extend only to $20 \mathrm{~km}$ south of a management area may shift its northern boundary northward, so that it now occurs in the area, which it had not previously occupied. Conflicts also arise with differences in scale among the values and priorities of different interest groups: while some focus keenly on the plight of single animals, others prioritize the conservation of species, or of populations, or ecological processes. It is important for managers and scientific advisors to recognize, and take seriously, ethical concerns whose scope may differ from their own.

We find several commonalities across our case studies: (1) people become accustomed to slow and incremental changes in distribution and abundance of introduced species (ie the "shifting baseline" of Hastings and Turner [1965]), through mismatches in timescales of human perception versus ecological changes; (2) the negative ecological impacts of a species might be important at one spatial scale, whereas their positive social impacts are more apparent (and influential) at a different spatial scale (eg horses and trout have national to international cultural importance but they exact ecological tolls at smaller scales); and (3) ecological processes (such as biological invasions) can extend beyond organizational and political borders and boundaries (Dallimer and Strange 2015) that constrain introduced-species management actions (eg urban parakeet management may be the responsibility of local authorities, for whom it is not a priority, but inaction could result in much more extensive impacts) (Figure 3).

Solutions to reconcile or reshape these social-ecological mismatches may emerge from multiple disciplines (eg sociology, economics, ecology), either alone or in concert. In many cases, an important first step involves conceptually mapping a management problem from multiple angles to identify where social-ecological mismatches may arise (Moon and Adams 2016). In terms of generating knowledge about the issue, in some cases insufficient attention to design and analysis considerations can compromise stakeholder perceptions of the reliability or trustworthiness of managing organizations and institutions. For example, to achieve the greatest level of scientific defensibility and prevent erosion of stakeholder trust, monitoring design and analytical methods should be robust, current, and quantitative; be sufficiently clear, consistent, and specific enough to be repeatable; and be structured to allow application to the target domain. Identifying and addressing mismatches between groups in species valuation and risk perception involves transparency in how knowledge is generated and interpreted, and the early participation of multiple stakeholders (including interested and affected parties at a range of scales) in decision-making processes. Inclusive, integrated, and iterative analytic-deliberative processes - such as structured decision making (Redpath et al. 2013; Guerrero et al. 2017) or multicriteria decision analyses (Davies et al. 2013) can improve communication and build trust among interested parties and ultimately lead to greater support for decisions (Estévez et al. 2015; Crowley et al. 2017). Adaptive manage-

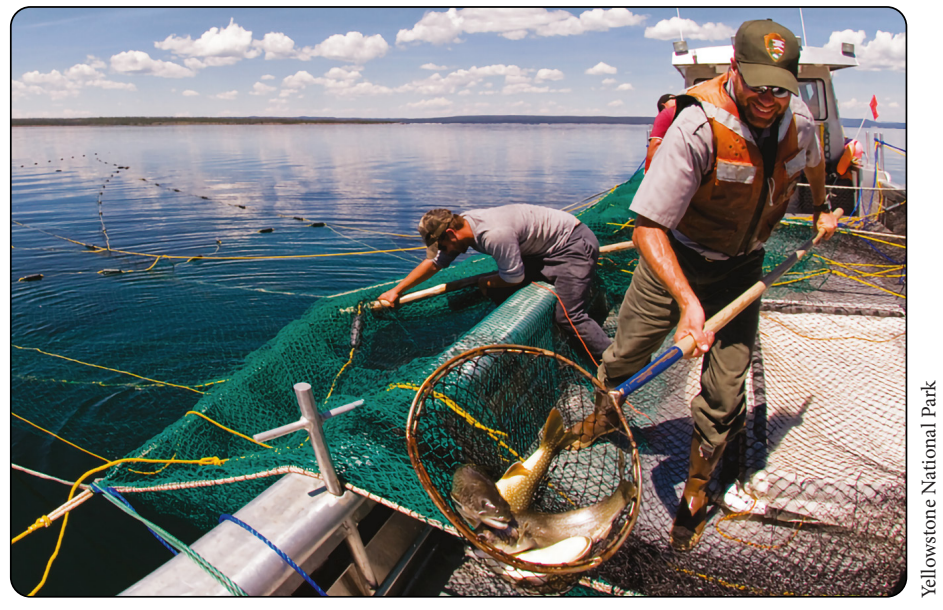

Figure 3. Example of management action used to limit unwanted ecological consequences of charismatic introduced species in conservation areas. Lake trout, which were illegally introduced from a nearby lake into Wyoming's Yellowstone Lake for recreational fishing in the 1980s and caused cascades of declines in native aquatic taxa, are currently being removed from streams and lakes in the Greater Yellowstone Ecosystem using gillnetting (shown here supplemented by a dip net holding four captured fish) and a naturally occurring chemical piscicide (rotenone) found in the roots, seeds, and leaves of several subtropical plants.

ment, clear demonstrations of the efficacy and necessity of proposed management methods, and a balance of flexibility (eg "stepped-down" regulations and guidance) and standardization may also help to reduce conflicts (NRC 2013). Linking principles, strategies, and expertise of the ecological and social sciences in collaborative efforts to build knowledge and seek solutions may help clarify sources of mismatches and lead to technically, socially, and ecologically feasible compromises to address challenging problems over multiple scales.

\section{Acknowledgements}

We thank L Eggert, K Laney, W Linklater, D Rubenstein, K Schoenecker, and D Wood for comments on earlier drafts. The case study of horses benefited from a panel convened by the National Academy of Sciences to review the science surrounding the Bureau of Land Management Wild Horse and Burro Program; EAB, SLP, and 12 others participated on the panel; L Huntsinger was particularly helpful. Any use of trade, firm, or product names is for descriptive purposes only and does not imply endorsement by the US Government.

\section{References}

Beever E. 2003. Management implications of the ecology of freeroaming horses in semi-arid ecosystems of the western United States. Wildlife Soc B 31: 887-95.

Beever EA. 2013. Equus caballus. In: Invasive species compendium. Wallingford, UK: Commonwealth Agricultural Bureaux International. 
Beever EA and Brussard PF. 2000. Charismatic megafauna or exotic pest? Interactions between popular perceptions of feral horses (Equus caballus) and their management and research. In: Salmon TP and Crabb AC (Eds). Proceedings of the 19th International Vertebrate Pest Conference. University of California, Davis.

Berman DM. 1991. The ecology of feral horses in central Australia (PhD thesis). Armidale, Australia: University of New England.

Bhattacharyya J and Murphy SD. 2015. Assessing the role of freeroaming horses in a social-ecological system. Environ Manage 56: 433-46.

Blanchet S, Loot G, Grenouillet G, and Brosse S. 2007. Competitive interactions between native and exotic salmonids: a combined field and laboratory demonstration. Ecol Freshw Fish 16: 13343.

Bockstael NE, Freeman AM, Kopp RJ, et al. 2000. On measuring economic values for nature. Environ Sci Technol 34: 1384-89.

Budy P, Thiede GP, Lobon-Cervia J, et al. 2013. Limitation and facilitation of one of the world's most invasive fish: an intercontinental comparison. Ecology 94: 356-67.

Crooks JA. 2011. Lag times. In: Simberloff D and Rejmánek M (Eds). Encyclopedia of biological invasions. Berkeley, CA: University of California Press.

Crowley SL, Hinchliffe S, and McDonald RA. 2017. Conflict in invasive species management. Front Ecol Environ 15: 133-41.

Crowley SL, Hinchliffe S, and McDonald RA. 2018. The parakeet protectors: understanding opposition to introduced species management. J Environ Manage; doi.org/10.1016/j.jenvman.2017. 11.036.

Cumming GS, Cumming DHM, and Redman CL. 2006. Scale mismatches in social-ecological systems: causes, consequences, and solutions. Ecol Soc 11: 14.

Dallimer M and Strange N. 2015. Why socio-political borders and boundaries matter in conservation. Trends Ecol Evol 30: 132-39.

Davies AL, Bryce R, and Redpath SM. 2013. Use of multicriteria decision analysis to address conservation conflicts. Conserv Biol 27: 936-44.

de Villalobos AES, Zalba M, and Peláez DV. 2011. Pinus halepensis invasion in mountain pampean grassland: effects of feral horses grazing on seedling establishment. Environ Res 111: 953-59.

Dobbie WR, Berman DM, and Braysher ML. 1993. Managing vertebrate pests: feral horses. Canberra, Australia: Australian Government Publishing Service.

Dudgeon D, Arthington AH, Gessner MO, et al. 2006. Freshwater biodiversity: importance, threats, status and conservation challenges. Biol Rev 81: 163-82.

Epstein G, Pittman J, Alexander SM, et al. 2015. Institutional fit and the sustainability of social-ecological systems. Curr Opin Env Sust 14: $34-40$.

Estévez RA, Anderson CB, Pizarro JC, and Burgman MA. 2015. Clarifying values, risk perceptions, and attitudes to resolve or avoid social conflicts in invasive species management. Conserv Biol 29: 19-30.

Fleury B. 2006. Kaimanawa wild horses: management versus passion. In: Dawson MJ, Lane C, and Saunders G (Eds). Proceedings of the National Feral Horse Management Workshop. Canberra, Australia: Invasive Animals Cooperative Research Centre.
García de Leaniz C, Gajardo G, and Consuegra S. 2010. From best to pest: changing perspectives on the impact of exotic salmonids in the Southern Hemisphere. Syst Biodivers 8: 447-59.

Garrott RA and Oli MK. 2013. A critical crossroad for BLM's wild horse program. Science 341: 847-48.

Guerrero AM, Shoo L, Iacona G, et al. 2017. Using structured decision-making to set restoration objectives when multiple values and preferences exist. Restor Ecol 25: 858-65.

Halverson A. 2011. An entirely synthetic fish: how rainbow trout beguiled America and overran the world. New Haven, CT: Yale University Press.

Hampson BA, Morton JM, Mills PC, et al. 2010. Monitoring distances travelled by horses using GPS tracking collars. Aust Vet J 88: $176-81$.

Hastings JR and Turner RM. 1965. The changing mile: an ecological study of vegetation change with time in the lower mile of an arid and semiarid region. Tucson, AZ: University of Arizona Press.

Jackson JE, Raadik TA, Lintermans M, and Hammer M. 2004. Alien salmonids in Australia: impediments to effective impact management, and future directions. New Zeal J Mar Fresh 38: 447-55.

Kadye WT, Chakona A, Marufu LT, and Samukange T. 2013. The impact of non-native rainbow trout within Afro-montane streams in eastern Zimbabwe. Hydrobiologia 720: 75-88.

Kellert SR and Berry JK. 1980. Phase III: knowledge, affection and basic attitudes toward animals in American society. Washington, DC: US Department of the Interior, Fish and Wildlife Service.

Klemetsen A, Amundsen PA, Dempson JB, et al. 2003. Atlantic salmon Salmo salar L, brown trout Salmo trutta L and Arctic charr Salvelinus alpinus (L): a review of aspects of their life histories. Ecol Freshw Fish 12: 1-59.

Kundu S, Faulkes CG, Greenwood AG, et al. 2012. Tracking viral evolution during a disease outbreak: the rapid and complete selective sweep of a circovirus in the endangered echo parakeet. J Virol 86: 5221-29.

Linklater WL, Cameron EZ, Minot EO, and Stafford KJ. 2004. Feral horse demography and population growth in the Kaimanawa Ranges, New Zealand. Wildlife Res 31: 119-28.

Linklater WL, Stafford KJ, Minot EO, and Cameron EZ. 2002. Researching feral horse ecology and behavior: turning political debate into opportunity. Wildlife Soc B 30: 644-50.

Lowe S, Browne M, Boudjelas S, and De Poorter M. 2004. 100 of the world's worst invasive alien species: a selection from the Global Invasive Species Database. Gland, Switzerland: International Union for Conservation of Nature.

Menchetti M and Mori E. 2014. Worldwide impact of alien parrots (Aves Psittaciformes) on native biodiversity and environment: a review. Ethol Ecol Evol 26: 172-94.

Menchetti M, Mori E, and Angelici FM. 2016. Effects of the recent world invasion by ring-necked parakeets Psittacula krameri. In: Angelici FM (Ed). Problematic wildlife. Cham, Switzerland: Springer.

Moon K and Adams VM. 2016. Using quantitative influence diagrams to map natural resource managers' mental models of invasive species management. Land Use Policy 50: 341-51. 
Morita K, Tsubo JI, and Matsuda H. 2004. The impact of exotic trout on native charr in a Japanese stream. J Appl Ecol 41: 962-72.

Muhlfeld CC, Kovach RP, Al-Chokhachy R, et al. 2017. Legacy introductions and climatic variation explain spatiotemporal patterns of invasive hybridization in a native trout. Glob Change Biol 23: 4663-74.

Nimmo DG and Miller KK. 2007. Ecological and human dimensions of management of feral horses in Australia: a review. Wildlife Res 34: $408-17$.

NRC (National Research Council). 2013. Using science to improve the BLM Wild Horse and Burro Program: a way forward. Washington, DC: National Academies Press.

Pauly D. 1995. Anecdotes and the shifting base-line syndrome of fisheries. Trends Ecol Evol 10: 430.

Redpath SM, Young J, Evely A, et al. 2013. Understanding and managing conservation conflicts. Trends Ecol Evol 28: 100-09.

Reino L, Figueira R, Beja P, et al. 2017. Networks of global bird invasion altered by regional trade ban. Science Advances 3: e1700783.

Rogers GM. 1991. Kaimanawa feral horses and their environmental impacts. New Zeal J Ecol 15: 49-64.

Simberloff D. 2011. The rise of modern invasion biology and American attitudes towards introduced species. In: Rotherham ID and Lambert RA (Eds). Invasive and introduced plants and animals: human perceptions, attitudes and approaches to management. London, UK: Earthscan.

Simberloff D, Martin JL, Genovesi P, et al. 2013. Impacts of biological invasions: what's what and the way forward. Trends Ecol Evol 28: 58-66.

Soga M and Gaston KJ. 2018. Shifting baseline syndrome: causes, consequences, and implications. Front Ecol Environ 16: 222-30.
Tatayah RVV, Malham J, Haverson P, et al. 2007. Design and provision of nest boxes for echo parakeets Psittacula eques in Black River Gorges National Park, Mauritius. Conserv Evi 4: 16-19.

Townsend CR. 2003. Individual, population, community, and ecosystem consequences of a fish invader in New Zealand streams. Conserv Biol 17: 38-47.

Vulink JT. 2001. Hungry herds: management of temperate lowland wetlands by grazing ( $\mathrm{PhD}$ thesis). Groningen, the Netherlands: University of Groningen.

Wiens JA and Bachelet D. 2010. Matching the multiple scales of conservation with the multiple scales of climate change. Conserv Biol 24: $51-62$.

Witmer GW and Hall P. 2011. Attempting to eradicate invasive Gambian giant pouched rats (Cricetomys gambianus) in the United States: lessons learned. In: Veitch CR, Clout MN, and Towns DR (Eds). Island invasives: eradication and management. Proceedings of the International Conference on Island Invasives. Gland, Switzerland and Auckland, NZ: International Union for Conservation of Nature and the Centre for Biodiversity and Biosecurity.

Young KA, Dunham JB, Stephenson JF, et al. 2010. A trial of two trouts: comparing the impacts of rainbow and brown trout on a native galaxiid. Anim Conserv 13: 399-410.

Zalba SM and Cozzani NC. 2004. The impact of feral horses on grassland bird communities in Argentina. Anim Conserv 7: 35-44.

\section{Supporting Information}

Additional, web-only material may be found in the online version of this article at http://onlinelibrary.wiley.com/ doi/10.1002/fee.2000/suppinfo 